\title{
Towards urban resilience through sustainable drainage systems: a multi- objective optimisation problem
}

Article

Accepted Version

Creative Commons: Attribution-Noncommercial-No Derivative Works 4.0

McClymont, K., Cunha, D. G. F., Maidment, C., Ashagre, B., Vasconcelos, A. F., de Macedo, M. B., dos Santos, M. F. N., Gomes Júnior, M. N., Mendiondo, E. M., Barbassa, A. P., Rajendran, L. and Imani, M. (2020) Towards urban resilience through sustainable drainage systems: a multi-objective optimisation problem. Journal of Environmental Management, 275. 111173. ISSN 0301-4797 doi:

https://doi.org/10.1016/j.jenvman.2020.111173 Available at https://centaur.reading.ac.uk/92740/

It is advisable to refer to the publisher's version if you intend to cite from the work. See Guidance on citing.

To link to this article DOI: http://dx.doi.org/10.1016/j.jenvman.2020.111173

Publisher: Elsevier

All outputs in CentAUR are protected by Intellectual Property Rights law, including copyright law. Copyright and IPR is retained by the creators or other copyright holders. Terms and conditions for use of this material are defined in the End User Agreement. 


\section{www.reading.ac.uk/centaur}

\section{CentAUR}

Central Archive at the University of Reading

Reading's research outputs online 


\title{
Towards Urban Resilience through Sustainable Drainage Systems: A Multi-objective Optimisation Problem ${ }^{1}$
}

Kent McClymont ${ }^{\mathrm{a}}$, Davi Gasparini Fernandes Cunha ${ }^{\mathrm{d}}$, Chris Maidment ${ }^{\mathrm{b}}$, Biniam Ashagre ${ }^{\mathrm{a}}$, Anaí Floriano Vasconcelos ${ }^{\mathrm{c}}$, Marina Batalini de Macedo $^{\mathrm{d}}$, Maria Fernanda Nóbrega dos Santos ${ }^{\mathrm{f}}$, Marcus Nóbrega Gomes Júnior ${ }^{\mathrm{d}}$, Eduardo Mario Mendiondo ${ }^{\mathrm{d}}$, Ademir Paceli Barbassa ${ }^{\mathrm{e}}$, Lakshmi Rajendran ${ }^{\mathrm{a}}$, Maryam Imani ${ }^{*}, \mathrm{a}$

\footnotetext{
a School of Engineering and the Built Environment, Bishop Hall Lane, Anglia Ruskin University, Essex, CM1 1SQ, UK

${ }^{\mathrm{b}}$ Real Estate and Planning, University of Reading, Whiteknights, Reading, RG6 6UD, UK c Natural Science Centre, Federal University of São Carlos, Buri, São Paulo, CEP 18290-000, Brazil ${ }^{\mathrm{d}}$ São Carlos School of Engineering, University of São Paulo, São Carlos, São Paulo, CEP 13560-590, Brazil ${ }^{e}$ Centre of Exact Sciences and Technology, Federal University of São Carlos, São Carlos, São Paulo, CEP 13565-905, Brazil ${ }^{\mathrm{f}}$ School of Architecture, Arts and Communication, São Paulo State University, Bauru, CEP 17033-360, Brazil
}

\section{Highlights}

- Urban resilience is a multi-objective task requiring a multi-disciplinary approach

- A primary feasibility study is key to identify suitable SuDS strategies in an area

- Integrated spatial optimisation of SuDS can enhance urban resilience planning

- SuDS investment should prioritise the inclusion of quality of life index

- Flood resilience and water quality resilience demonstrate some correlations

\begin{abstract}
The necessity of incorporating a resilience-informed approach into urban planning and its decision-making is felt now more than any time previously, particularly in low and middle income countries.

In order to achieve a successful transition to sustainable, resilient and cost-effective cities, there is a growing attention given to more effective integration of nature-based solutions, such as Sustainable Drainage Systems (SuDS), with other urban components. The experience of SuDS integration with urban planning, in developed cities, has proven to be an effective strategy with a wide range of advantages and lower costs. The effective design and implementation of SuDS requires a multi-objective approach by which all four pillars of SuDS design (i.e., water quality, water quantity, amenity and biodiversity) are considered in connection to other urban, social, and economic aspects and constraints. This study develops a resiliencedriven multi-objective optimisation model aiming to provide a Pareto-front of optimised solutions for effective incorporation of SuDS into (peri)urban planning, applied to a case study in Brazil. This model adopts the SuDS's two pillars of water quality and water quantity as the optimisation objectives with its level of spatial distribution as decision variables. Also, an improved quality of life index (iQoL) is developed to re-evaluate the optimal engineering solutions to encompass the amenity and biodiversity pillars of SuDS. Rain barrels, green roofs, bio-retention tanks, vegetation grass swales and permeable pavements are the suitable SuDS options identified in this study. The findings show that the most resilient solutions are costly but this does not guarantee higher iQoL values. Bio-retention tanks and grass swales play effective roles in promotion of water quality resilience but this comes with considerable increase in costs. Permeable pavements and green roofs are effective strategies when flood resilience is a priority. Rain barrel is a preferred solution due to the dominance of residential areas in the study area and the lower cost of this option.
\end{abstract}

Keywords: Green infrastructure, Multi-objective optimisation, Resilience, Sustainable drainage systems, Urban planning, Quality of life.

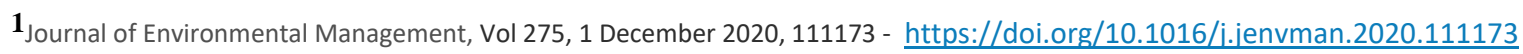




\section{Introduction}

The impacts of climate change and their interaction with rapid urbanisation are particularly tangible in developing countries of the tropics and subtropics (Grimm et al., 2008; Lim and Lu, 2016; Zhang et al., 2019). In some regions, such shifts will likely increase the frequency and intensity of extreme events that can trigger floods, exacerbated by the construction of marginal settlements in risk-prone areas, such as floodplains and unstable slopes, with inadequate drainage infrastructure and unenforced building codes (UN-Habitat, 2003; UN-Habitat, 2010; Mendelsohn et al., 2012; UN-Habitat, 2013; IPCC, 2014; UNISDR, 2015; Capps et al., 2016; Mendes et al., 2018). This combination can be expected to tip into disruptive surface runoffs and/or flooding, leading to environmental, social and economic costs and drawbacks in communities that have the least capacity to address them (Hallegatte and Rozenberg, 2017; Jongman, 2018; Bevacqua et al., 2019).

In this paper, we demonstrate a novel, resilience-driven multi-objective optimisation model developed to aid decision-makers in selecting appropriate types of Sustainable Drainage Systems (SuDS) for areas facing these issues. This feasibility study demonstrates how utilising a multi-objective optimisation approach to integrate the four pillars of SuDS design; water quality, water quantity, amenity and biodiversity (Woods Ballard et al., 2015), can, not only improve flood and water quality resilience, but also improve quality of life for the communities inhabiting these (peri)urban areas. The approach has been tested for a (peri)urban case study with extreme wet and dry periods in Brazil. The decision to choose a Brazilian case, encompassing a diversity of communities and land-uses, allowed the study to include marginalised communities. These communities are likely to see the greatest adverse effects of flooding and therefore stand to benefit the most from interventions that increase resilience to flooding. In addition, the still evolving regulatory environment in Brazil allows more scope to embed a more holistic understanding of drainage, when compared to the more mature and codified nature of regulation in countries such as the UK.

Addressing this need for (peri)urban areas to have the capacity to respond to extreme climate-induced conditions such as floods, droughts, precipitations, and temperature (Pelling, 2003; Leichenko, 2011; Koning et al., 2019), urban resilience has been defined as "the capacity of individuals, communities, institutions, businesses, and systems within a city to survive, adapt, and grow no matter what kinds of chronic stresses and acute shocks they experience" (100ResilientCities, 2016, p. 16). With growing attention to urban resilience, nature-based solutions (NBS), such as SuDS, have proved to be effective intervention strategies due to their wide range of advantages for urban areas (Jia et al., 2013; Qin et al., 2013; Fletcher et al., 2015). Therefore, to achieve a successful transition to urban resilience, there needs to be more effective integration of SuDS, with other forms of urban development such as transport infrastructure, buildings, public spaces and so on. Accordingly, the purpose of this study is to show how novel, socially and ecologically minded approaches to urban resilience can be applied to countries undergoing rapid, often poorly managed development of their (peri)urban areas, whilst simultaneously facing the extreme events associated with climate change.

In line with this, several conceptual frameworks have been proposed in the literature to formulate urban resilience with incorporation of the four pillars of SuDS design (e.g. Tyler and Moench, 2012; SánchezRodríguez, 2009; Sisto et al., 2016). Wang et al. (2017) developed a resilience-informed framework for decision making in SuDS designed to avoid any subjectivity in the decision-making process. A review of evidence for improved urban resilience by implementing SuDS and NBS was carried out by Lamond et al. (2015) and Frantzeskaki (2019) to further reinforce the multi-dimensionality of decision making related to SuDS. Some studies have used (urban) resilience as a performance metric to assess SuDS options using a multi-objective approach (Wang et al., 2017; Casal-Campos et al., 2018). Nevertheless, whilst the importance of incorporating SuDS in the promotion of urban resilience has been widely acknowledged, to date, a model achieving full integration is yet to be developed.

Simultaneously, the complex and dynamic nature of urban resilience requires an integrated and multidisciplinary approach by which all the stakeholders such as infrastructure owners, urban planners, 
communities, regulators and operators can communicate, share their knowledge and experience and learn from each other to co-create solutions (Desouza and Flanery, 2013; Jabareen, 2013; Aguilar-Barajas et al., 2019). This can produce trade-offs, starting from conflicting objectives, by which all the stakeholders' views and needs are addressed (Chelleri, et al., 2015; Dhar and Khirfan, 2017). This is an even greater challenge in tropical and sub-tropical countries (such as Brazil), where the extreme climatic conditions can lead to deeper conflicts between stakeholders, and where this is further compounded by the often more acute nature of the financial challenge. Hence, effective SuDS implementation to promote urban resilience requires a multi-criteria approach by which a trade-off of best solutions can be produced to address the concerns of all stakeholders and aid effective decision-making. To date of this paper, such model is yet to be developed.

To address this gap, this study embraces the multi-dimensionality, multi-objectivity and nonlinearity of urban resilience by developing a novel resilience-driven multi-objective optimisation model, to provide a Pareto-front of optimised solutions, with the aim of incorporating more effective SuDS solutions into urban planning decisions. This model builds on the four pillars of SuDS design in the UK SuDS Manual (Woods Ballard, et al., 2015) to embrace the engineering, environmental, social, and economic aspects of SuDS adoption and implementation, in order to promote urban resilience.

\section{Materials and Methods}

A common optimisation approach was adopted to explore the impact of SuDS incorporation on the resilience of a case study catchment in Brazil, optimising the arrangement and application of different SuDS options. Firstly, the case study area (introduced in Section 2.1) was simulated using standard modelling software, providing the basis of the optimisation objective functions and, also, the SuDS feasibility map (Section 2.2). Following an overview of the SuDS capital cost calculations in this study (Section 2.3), urban resilience is defined and characterised in Section 2.4, collectively introducing the optimisation model objectives. A novel improved Quality of Life (iQoL) index, created to assess some of the social impacts of the generated solutions and is introduced in Section 2.5. This index intends to give additional context for decision-makers when choosing which solution to adopt. Section 2.6 describes how these aspects are brought together into a multi-objective optimisation model. Finally, the details of the resilience-informed optimisation model (a standard Evolution Strategy algorithm) are discussed in Section 2.6.

\subsection{Study area}

The study area is a sub-catchment of the Mineirinho catchment (geographic coordinates: 22 ${ }^{\circ} 00^{\prime}$ $50.66^{\prime \prime} \mathrm{S}, 47^{\circ} 54^{\prime} 45.37^{\prime \prime} \mathrm{W}$ ) located within the city of São Carlos in the southeast of Brazil, centrally within the state of São Paulo (Fig. 1a). São Carlos has an area of $141 \mathrm{~km}^{2}$ and 249,415 inhabitants (IBGE, 2015). The city has an altitude tropical climate with dry winter and a minimum average temperature of $15.3^{\circ} \mathrm{C}$ and maximum of $27.0^{\circ} \mathrm{C}$ during summer. January and February are usually the wet periods, and June and July, the dry periods with an average monthly rainfall of $270 \mathrm{~mm}$ and $15 \mathrm{~mm}$, respectively. The Master Plan of São Carlos (PMSC, 2016), designates this area as intended for different land-uses, with places reserved for preservation of streams, as well as areas foreseen for future residential expansions.

The Mineirinho catchment has a history of recurrent flooding, particularly over the past decade, leading to significant economic loss due to growing commercial establishments in the city (Fava et al., 2018; de Abreu et al., 2019). There have been attempts to manage this regular flooding by rectifying and/or channelizing the rivers and streams within the city leading to exacerbation of flooding in the city's lowlands. In addition, illegal discharges of sewage to rivers, suppression of vegetation in canopy areas and permanent preservation areas, lack of green areas, lack of suitable waste disposal sites, erosion processes, sedimentation of streams and rivers, have led to deterioration of surface water quality (Pons et al., 2007; Stanganini and Augusto de Lollo, 2018).

The study area covers an area of approximately $6.86 \mathrm{~km}^{2}$, on the boundary between urban and periurban areas in the northwest part of São Carlos (Fig. 1b). Its main river is Mineirinho River (with a length 
of $3.15 \mathrm{~km}$ ) with two joining tributary streams of the Santa Fé and the University of São Paulo's (USP) Campus II (Fig. 1b). The former flows through mainly deprived and informal developments (north east of the catchment) with high level of water contamination and the latter flows through newly developed/under development areas, including USP's new campus (north-west of the catchment) and is environmentally in a better condition. To the south-west of this area, there are new, formally planned developments which socially and environmentally could be categorised as 'in a good condition'.

Therefore, the Mineirinho catchment has been recognised as a suitable case study primarily due to its growing environmental challenges (such as flooding and surface water pollution). Furthermore, the impacts of SuDS, as the core intervention, can be studied in a more comprehensive and inclusive manner due to the diverse demography and varying levels of marginalisation/formality in this area.

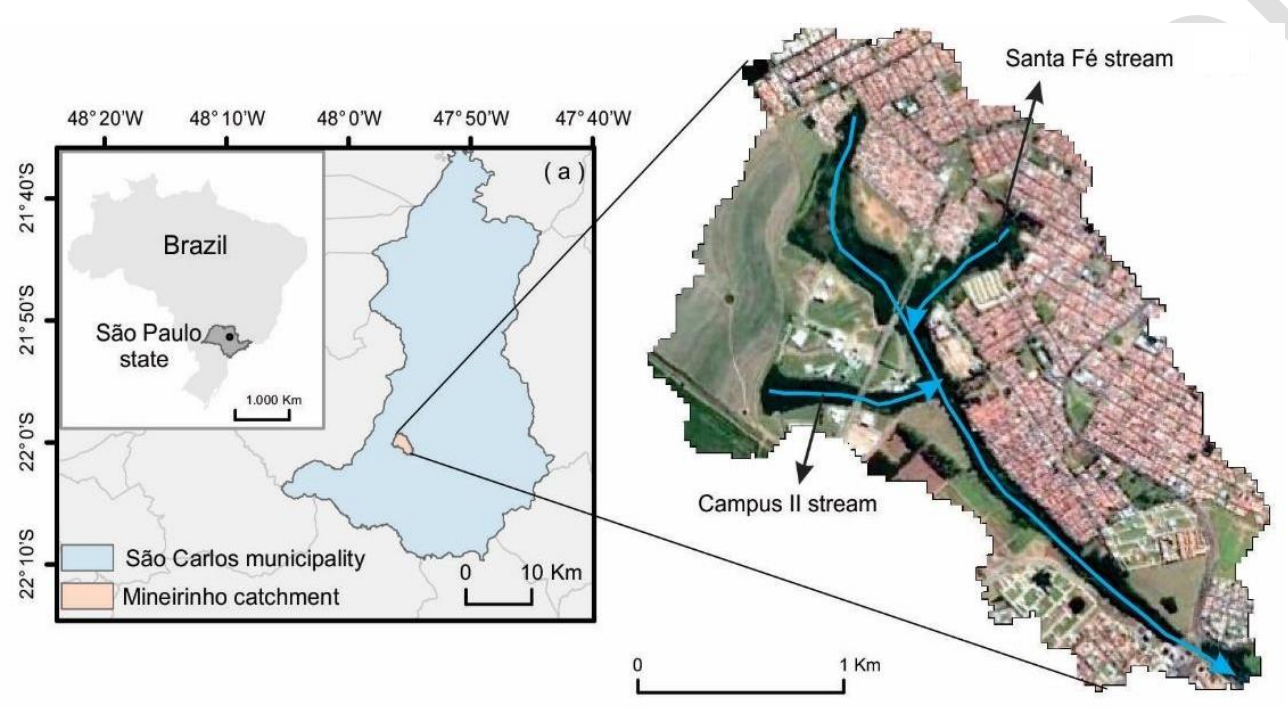

(a)

(b)

Fig. 1. (a) Mineirinho catchment; (b) Mineirinho river and the two joining streams of Campus II and Santa Fé

Although, this research focuses on the aforementioned case study area, its environmental, social and urban conditions are similar to many other catchments in Brazil. Therefore, the scope of this study can be applied to other Brazilian catchments with similar SuDS incorporation challenges, although with different environmental conditions. Consequently, the outcomes could be replicated in those areas to achieve more effective SuDS planning and subsequently create opportunities to embrace sustainable urban development pathways. In addition, the manageable size of the catchment made it suitable for multi-objective optimisation simulations by reducing long computational time of the process-based models utilised in this case study. For simplicity, the term 'Mineirinho catchment' is used throughout the paper and it implies the study area modelled in this research (which is part of the Mineirinho catchment).

InfoSWMM® was used in this study for simulating the case study area and incorporating SuDS into it. This provides the objectives' measure for calculating the performance of different solutions in the optimisation process. Details of the simulation model development can be found in supplementary information accompanying this paper (Section 2 in supplementary information).

To generate more realistic flood inducing rainfall, a 10-yr two-stage design storm rainfall pattern using Huff Heavy Storm equations (Huff, 1967) are used (see Fig. 2 in supplementary information). This design storm was suitable given the calibration data provided and represented a realistically foreseeable horizon, given the rate of development and change in the area. Additionally, in the state of São Paulo (where the case study is located), the local design standards recommend 10-yr rainfall as an efficient figure to design 
and analyse micro-drainage and also SuDS systems (Municipality of São Paulo, 2012). Furthermore, this approach can stress the catchment to more clearly identify appropriate solutions, which were more resilient to reasonably expected future increases in sudden rainfall and climate changes, without such extreme rainfall that makes objectively comparing solutions more difficult.

As stated, the study area is an ungauged catchment leading to the lack of accurate and reliable data for detailed calibration of the model. However, throughout the model development stage, local expert knowledge, judgements and studies have been utilised to ensure that the model developed can represent real-life conditions in the case study area.

\subsection{Implementation of SuDS}

In the UK SuDS manual (Woods Ballard, et al., 2015; CIRIA, 2007), 14 types of SuDS have been introduced. The characteristics of the case study catchment have driven the selection of the types and potential locations of SuDS. In consultation with local experts, green roofs (GNR), rain barrel (RNB), permeable pavement (PVP), vegetation grass swale (GSW) and bio-retention tanks (BIR) were identified as potentially the most suitable strategies in the Mineirinho catchment. The GIS-enabled InfoSWMMSustain is used in this study to identify the potential areas for each SuDS option. It is assumed that GNR can be implemented on roof areas of only commercial and industrial buildings, and RNB only on residential buildings due to affordability issues. PVP and GSW are implemented along access and main roads (sidewalks/pavements) and in public car parks, BIR in any public grassland or open space (See Fig. 2a). This study has only focused on the essential hydraulic design parameters utilised in InfoSWMM $®$ and the values of these parameters were adopted from Brazilian documents, consultation with local experts and from compatible resources in the literature (Woods Ballard et al., 2015) that best fit the conditions of the Mineirinho catchment (see Table 3 to Table 7 in supplementary information for more details on SuDS design). The potential areas for each SuDS option have been mapped in Fig. $2 \mathrm{~b}$.

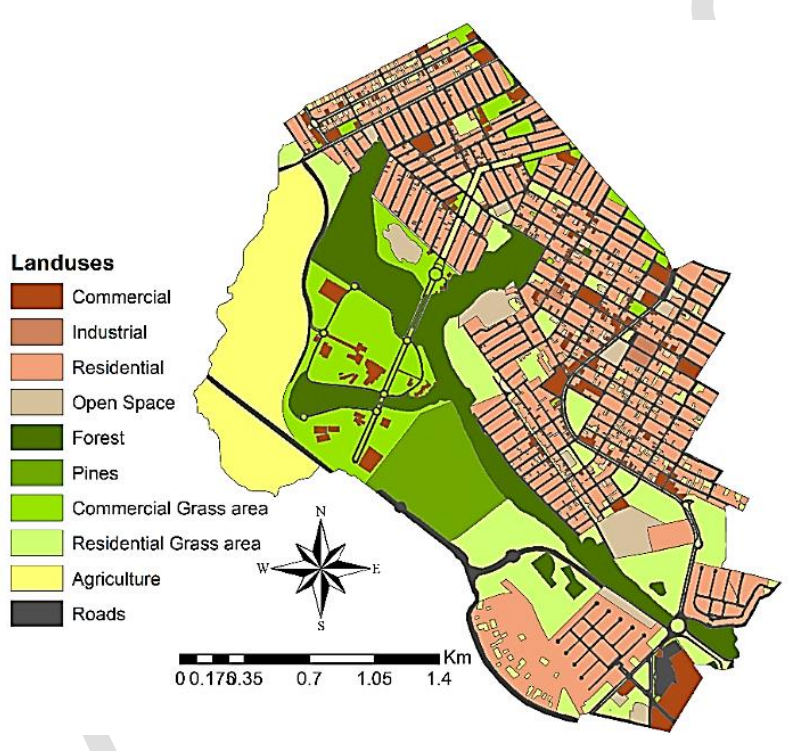

(a)

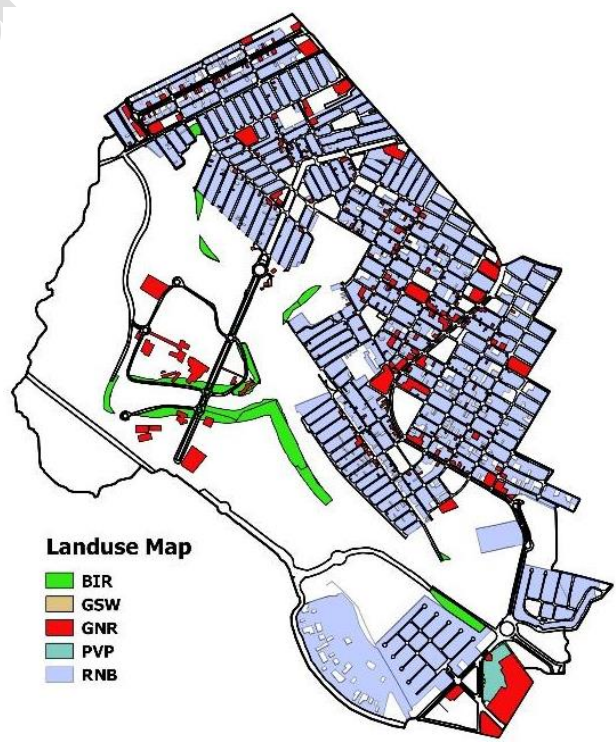

(b)

Fig. 2. (a) Land-use map; (b) SuDS feasibility map in the Mineirinho catchment

\subsection{SuDS capital costs}

The cost of constructing SuDS varies depending on the size of the associated catchment area, the proposed design and construction methods. There are a few studies on SuDS construction costs in Brazil, but the methods utilized are not standardized and the data used are outdated. It would be necessary to 
restructure and update these documents before use, which would require intensive time and effort beyond the scope of this research. Thus, this study adopts the UK Environment Agency's (EA) method for calculation of SuDS capital costs through the unit costs values published in a report by Keating et al. (2015). The proposed unit cost values by the EA are based on actual costs from a number of projects within the UK and a wider literature review by the EA. In this study, the capital costs are split into two parts of construction and maintenance costs, as detailed in Section 3 in supplementary information. For this study, the unit area is calculated by the average area of randomly picked houses in the informal and formal developments in the study area. The average area of a residential property in the Mineirinho catchment, using Google satellite images from 2017, is estimated around $158 \mathrm{~m}^{2}$. The maintenance cost is calculated using an average frequency of maintenance per year and unit cost of maintenance per unit area of each SuDS type.

\subsection{Urban resilience evaluation}

This study defines 'urban resilience' as the 'ability of the urban and its peri-urban areas to maintain their continuity through climate change and urbanisation while adapting and transforming'. Drawing on this, 'urban resilience' is characterised collectively as flood and water quality resilience. Increased rainfall and informal/unplanned developments represent, respectively, climate change and urbanisation in this study. SuDS strategies are then used as intervention strategies to tackle water pollution and flooding problems, mitigating the impacts of flooding on communities, whilst also providing some benefits for dayto-day life.

\subsubsection{Flood resilience}

This study adopts a volumetric approach to calculate flood resilience (Mugume and Butler, 2016). In this method, the total flood volume relative to the total flow in the drainage network, channel/river/stream and the ratio of the total duration of flooding to the total study time are calculated using Equation 1.

$$
\operatorname{Res}_{f}=1-\left[\frac{V_{F}}{V_{T}}\right] \times\left[\frac{t_{F}}{T}\right]
$$

where, Resf: flood resilience; $V_{F}$ : total flood volume $\left[\mathrm{m}^{3}\right] ; V_{T}$ : total flow volume during flooding $\left[\mathrm{m}^{3}\right]$; $t_{F}$ : total duration of flooding $[h r] ;$ and $T$ : total study time period $[h r]$.

\subsubsection{Water quality resilience}

In this study, a pollutant concentration-based approach is used, where the increase or reduction in pollutant load over time, is taken as an indicator for water quality resilience measure. Total Suspended Solids (TSS), Total Phosphorus (TP), and Total Nitrogen (TN) are recognised as the most critical water pollutants in the study area by the local experts. The National Council for the Environment (CONAMA)'s resolution (CONAMA, 2005) is used for threshold concentration of the water quality parameters. Water pollution is then defined as the breach of water quality standards' thresholds. All water quality measurements have been conducted in the catchment's recipient river in downstream at the outfall node. Equation 2 is then used to calculate water quality resilience.

$$
\operatorname{Res}_{W Q_{i}}=1-\left[\frac{W Q_{T B_{i}}}{W Q_{T C_{i}}}\right] \times\left[\frac{t_{T B}}{T}\right]
$$

where, $i$ : water quality parameter index (1: TSS; $2: \mathrm{TP} ; 3: \mathrm{TN}) ; \operatorname{Res}_{W Q_{i}}:$ water quality resilience; $W Q_{T B_{i}}$ : cumulative breach of water quality standard threshold $[m g / l] ; W Q_{T C_{i}}$ : cumulative water quality standard threshold compliance over the study period $[m g / l] ; t_{T B}$ : total duration of water contamination, $[\mathrm{hr}] ; \mathrm{T}$ : total study time $[h r]$.

This study adopts a more conservative approach and uses the lowest water quality resilience value calculated to represent the water quality resilience of the study area (see Equation 3). 


$$
\operatorname{Res}_{W Q}=\min \left[\operatorname{Res}_{W Q_{i}}, \operatorname{Res}_{W Q_{j}}, \operatorname{Res}_{W Q_{k}}\right]
$$

where, $i, j, k$ : water quality indexes for TSS, TP, TN, respectively; $\operatorname{Res}_{W Q}$ : total water quality resilience; $\operatorname{Res}_{W Q_{i}}$ : water quality resilience for TSS; $\operatorname{Res}_{W Q_{j}}$ : water quality resilience for TP; $\operatorname{Re}_{W Q_{k}}$ : water quality resilience for $\mathrm{TN}$.

It should be noted that the value of resilience is scaled between 0 and 1 ( 1 means the system is resilient and zero means no resiliency). Also, a hypothetical resilience curve can be found in Fig. 1 in supplementary information.

\subsection{Improved quality of life index}

In recognition of the potential for well-designed SuDS to also contribute to wider improvements in existing day-to-day quality of life, this study tested an improved quality of life index (iQoL). This index is designed to give the amenity and biodiversity pillars of SuDS design (Woods Ballard et al., 2015) clear weight in urban planning decisions. A methodology adapted from Sustainability Appraisal (SA) for planmaking in the English urban planning system (UK Statutory Instruments, 2004) was used to translate qualitative judgements about quality of life benefits associated with the five selected SuDS types into quantitative 'scores', whilst maintaining transparency about how this was undertaken. For this purpose, direct and potential benefits have been identified and scored in three categories of Physical Health and Wellbeing, Social Wellbeing and Ecosystem Services, to derive a simple iQoL for each SuDS type, as outlined in Table 1. Benefits are categorised into those which are inherent to the SuDS type (direct benefits, highlighted grey) and those which depend on the detailed design and specification of the SuDS type (potential benefits). In this method direct benefits are given full weight; +0.10 and any potential benefit half weight; +0.05 . As a default the weightings are set evenly as 1 for all SuDS type. Then, the total weight is the sum of direct and potential benefits, added to 1, and represents the iQoL for each SuDS type.

Table 1 - iQoL per unit area of the selected SuDS types

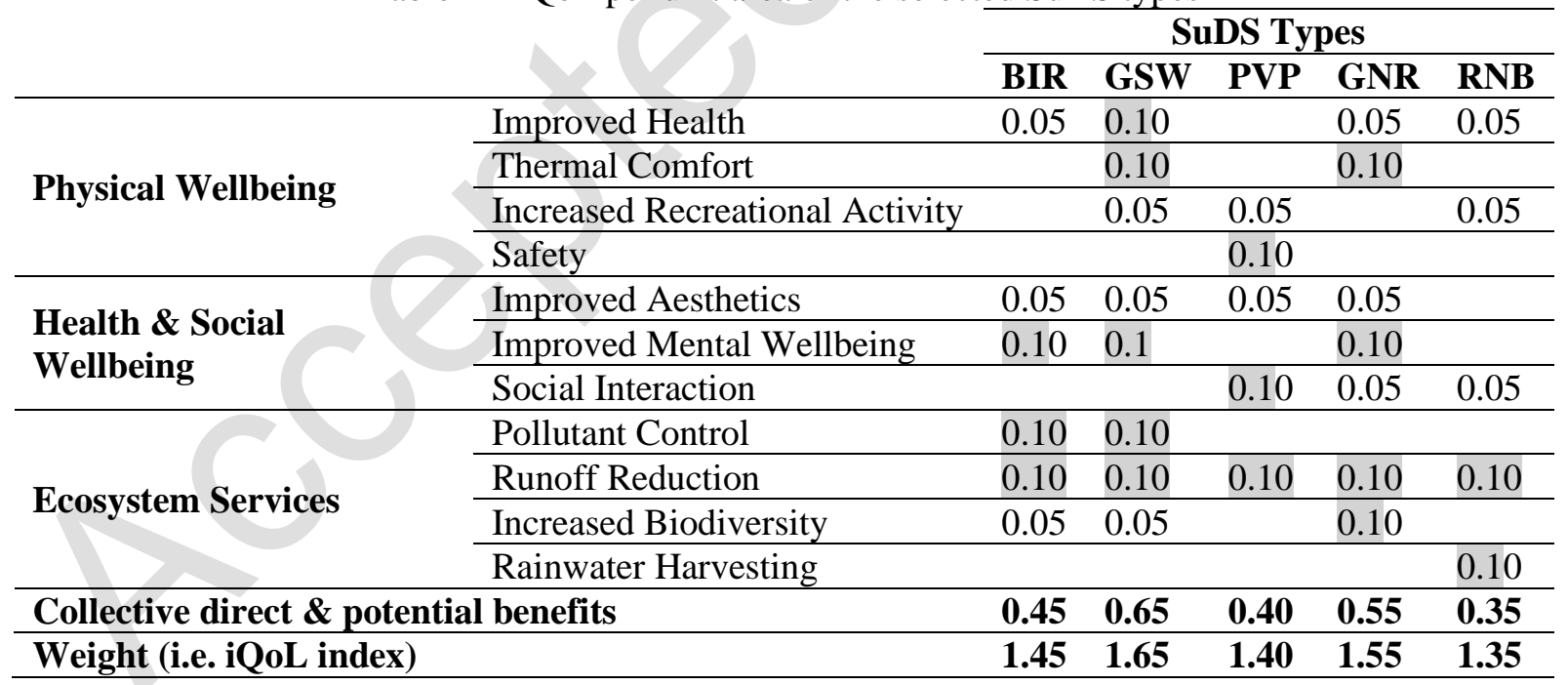

Alternative approaches to accounting for these benefits have been tested. A well-known example is the B£ST tool (CIRIA, 2015), which assigns financial values to wider 'amenity' benefits through their impact on increased local property prices. This can be argued to generate more 'objective' data that could be included in the model as a fourth optimisation model. However, the financialization of these benefits conflicts with the intended applicability of the model in diverse urban environments, including marginalised communities, where any financial benefit may never be realised.

The iQoL index instead recognises the intrinsic nature of quality of life benefits by giving them all equal weight. These scores could be used as a direct input into the optimisation model, translating fundamentally 
subjective 'quality of life' benefits into a direct influence on the optimal Pareto-front solutions that are generated. However, it was judged that the scores' relative subjectivity would render their use as a direct input misleading when compared to other data sources drawn upon in the modelling. Instead, all the optimal Pareto-front solutions generated by optimising for the other three objectives are evaluated for their iQoL value and scaled between 0 and 1 in order to investigate the suitability of the engineering solutions in terms of their social aspects.

It should be noted that the iQoL is a dimensionless weight and could be applied to either the total number of SuDS units or to per unit area of SuDS. In this study, the latter approach is used. Therefore, iQoL is calculated as the accumulated weight of all feasible SuDS coverage in each sub-catchment as shown in Equation (4).

$$
i Q o L=\sum_{i=1}^{n} \sum_{j=1}^{m}\left(W_{j} \times A_{i j}\right)
$$

where, $i$ : index of the sub-catchment; $n$ : total number of sub-catchments (50 in this study); $j$ : index associated to each SuDS type ( $\mathrm{j}=1,2,3,4,5$; see Table 2$) ; m$ : total number of SuDS options; $W_{j}$ : each SuDS type's weight per unit area of coverage illustrated in Table 2; and $A_{i j}$ : total area coverage of the SuDS type $j$ in sub-catchment $i$.

\subsection{Multi-objective optimisation model}

The multi-objective nature of urban resilience requires consideration of sometimes conflicting objectives such as environmental, social, and economic. The advantage of using a multi-objective optimisation approach in supporting decision-making processes has been clearly identified by several studies (Fu et al., 2008; Astaraie-Imani et al., 2012). In this study MATLAB®; a standard Evolution Strategy (Beyer and Schwefel, 2002) with a mutation and cross-over operator, similar to a Genetic Algorithm like NSGA-II, has been used for the optimisation of SuDS solutions. Because of the nature of the problem, solutions were encoded as a sequence of SuDS types (categorical) and number of SuDS implemented (positive integer scalar), applied to each catchment. The type and number of SuDS was constrained in each catchment based on the land use and percentage coverage of the area. An elite archive of the Pareto Optimal solutions was maintained to ensure no optimal solutions were lost during the search.

\subsubsection{Optimisation model objectives}

The study considers a three-objective optimisation model, as follows: maximising flood resilience (FRes) through SuDS implementation; maximising water quality resilience (WQRes) through SuDS implementation; and minimising SuDS capital costs. It should be noted that FRes and WQRes values are scaled between 0 and 1 (1: the system is resilient; 0 : the system fails all the time without any recovery). As noted, the iQoL score was not used as an objective function as it provides a social aspect to examining different solutions produced by the optimisation method and offers a non-engineering perspective for decision makers. Future work would look to further calibrate and develop iQoL to make it more suitable for inclusion as an objective measure.

\subsubsection{Optimisation model decision variables}

The decision variables can be seen either as SuDS design parameters (e.g. height, slope, thickness, roughness etc.), and/or as the area of coverage for each SuDS unit in a sub-catchment. A combination of both the area of coverage and the design parameters can lead to the most reliable solutions, however, such an approach is computationally demanding. Hence, this study uses a fixed design approach for the selected SuDS design parameters and only utilises the area of coverage by each SuDS unit, within each subcatchment of the Mineirinho catchment, as the optimisation decision variable. There the upper boundary for the decision variables defined is the maximum potential area within a sub-catchment as shown in Fig. $2 \mathrm{~b}$ and the lower boundary will be zero (i.e. no SuDS is needed). 


\section{Results and Discussion}

\subsection{Optimisation convergence}

The Evolution Strategy (ES) was set up to run for 2,000 generations with a population of 100 nonduplicate solutions to allow for convergence on globally optimal results. Fig. 3a shows the convergence of solutions over generations with the search settling on the lowest cost values around generation 1,200. Fig. $3 \mathrm{~b}$ shows the most common application of SuDS to each sub-catchment at each generation. This plot demonstrates the search focusing on a similar set of solutions, confirming the convergence seen in Fig. 3a, and indicating that the optimiser was able to explore local areas of high-quality solutions (i.e. higher resiliency, lower costs).
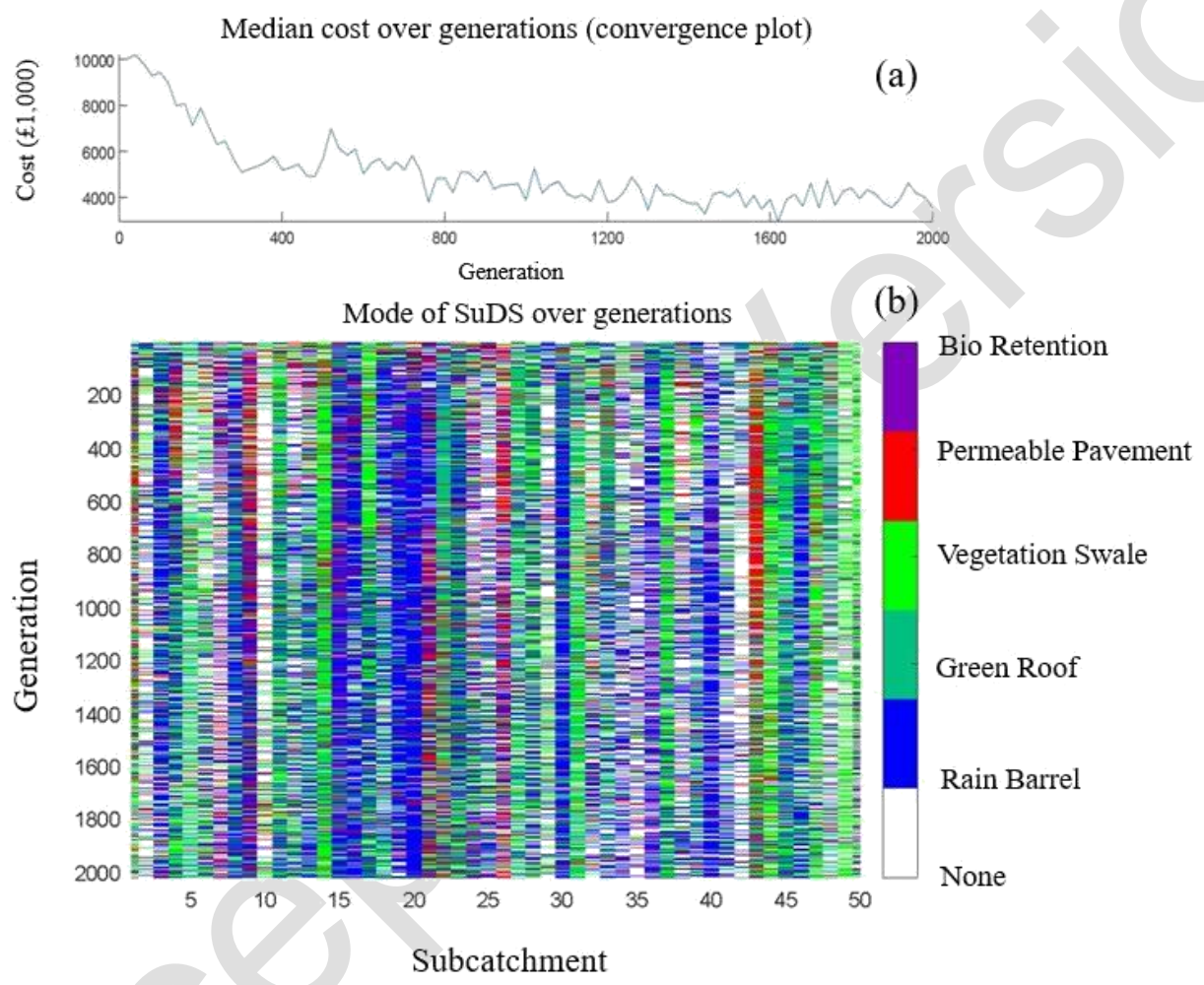

Fig. 3 - (a) Convergence plot of the population (which includes non-optimal solutions) on optimal cost solutions; (b) Image Scale Matrix plot of the most common SuDS selection for each sub-catchment over generations.

\subsection{Pareto optimal solutions}

Fig. 4 shows the Pareto-front of optimal solutions obtained in the ES search using three paired objective plots illustrating trade-offs and one 3D plot to show the shape of the front (Fig. 4d). The base case of no SuDS (no-SuDS scenario) was evaluated but not shown in this plot to preserve scale. The base case was evaluated to have FRes of 0.653 and WQRes of 0.426 . Additionally, primary investigations using the landuse map in Fig. 2b, identified $40 \%$ of the area feasible for implementation of the SuDS types chosen. The iQoL value (normalised between 0 and 1; 0: low iQoL value and 1: high iQoL value) is shown by each point's colouring in Fig. 4. 
In total only 63 Pareto optimal solutions were found by the search, highlighting the difficulty of the search space and challenge in finding smooth trade-offs in a hard mixed combinatorial-scalar problem (choice of SuDS and how many units). The

Fig. 4a shows a classic knee trade-off between Cost and FRes, with diminishing returns on investment roughly after $£ 2.0 \mathrm{M}$. In this figure an almost $20 \%$ improvement to FRes in comparison to the no-SuDS scenario, as a result of SuDS incorporation, can be observed. This implies that more investment in SuDS will not always guarantee significant improvements to FRes. Such a strong knee feature would suggest to decision-makers that those solutions will give a preferable return on investment. A similar, but weaker trade-off can also be observed between Cost and WQRes in Fig. 4b. However, WQRes is nearly doubled in comparison to the no-SuDS scenario. This highlights the effectiveness of implementing SuDS as water pollution control in the study area. There is a defined "step" or "shelf" in the front created by a drop in WQRes in exchange for the higher FRes to Cost trade-off. This can be seen by the two strata in Fig. 4b and Fig. 4c. The effect of this step is more clearly seen in Fig. 4d, where the upper shelf is seen in the context of all three objectives. Several optimisation runs were made and this shelf feature was observed in every set of results. This observation has two folds to justify: first, stochasticity inherently influences optimisation because of not only scaling effects but also collinearity. Scaling effects in optimising SuDS arise due to spatial and temporal aggregation of the explanatory variables; second, resilience formulation, as an optimisation objective, which is a function of two variables creating a trade-off between flood resilience and water quality resilience on a sub-catchment level. Given the inherent interrelationship between water quality and quantity, a stronger correlation between WQRes and FRes could be expected, however, the observations in Fig. 4c do not produce this effect.

(a)
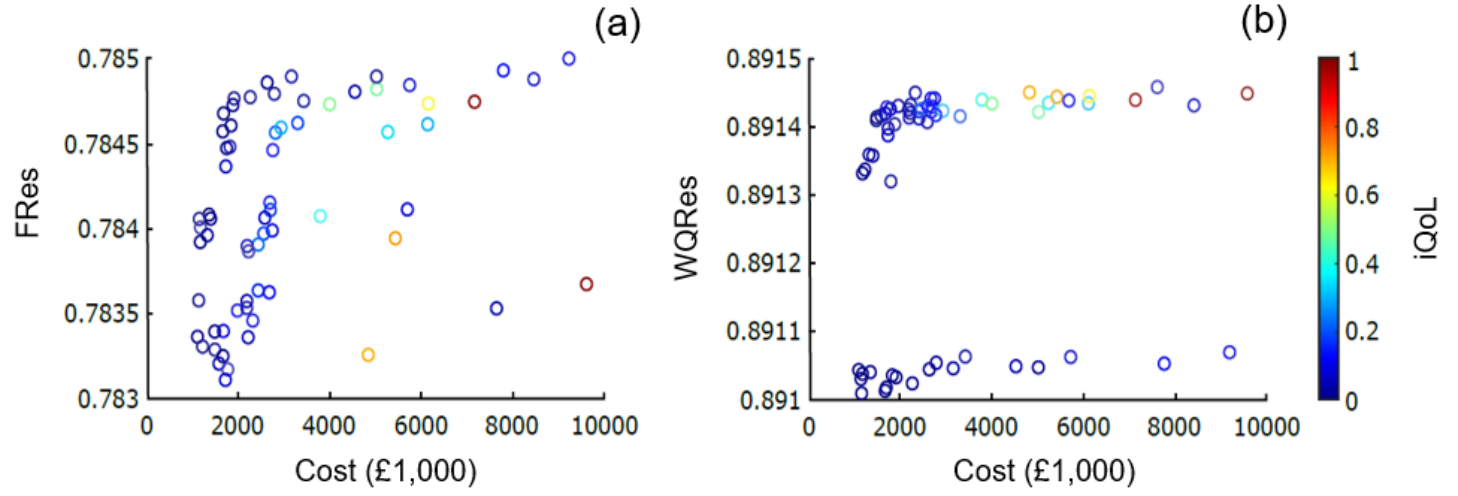

(c)
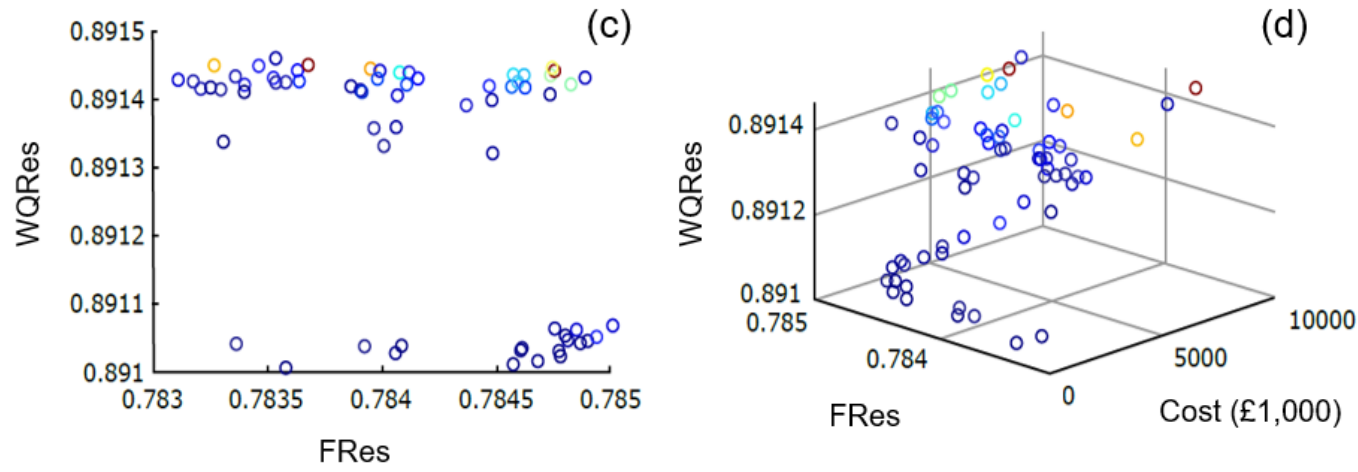

(d)

Fig. 4 - (a), (b), (c) 2D plots showing bi-objective trade-offs and iQoL index; (d) 3D plot showing the Pareto-Front

Overall, the results suggest a correlation between iQoL and a combined increase in Cost and in WQRes and FRes (Fig. 4b). It should be noted that without the inclusion of WQRes in the objective analysis of solutions, the optimisation algorithm would have focused on the lower step of results (e.g. Fig. 4b and Fig. 
4c) - those sacrificing WQRes and smaller improvements in iQoL for marginal improvements in FRes and Cost (Fig. 4a). This highlights the importance of SuDS selection thorough feasibility study and its impacts on the defined objectives. Additionally, this will stress the prominence of allocating the right SuDS option in the right place (i.e. each sub-catchment). In addition to picking the right objectives, these results further reinforce the utility of a multi-objective optimisation approach to support effective, resilience-informed decision-making for SuDS incorporation into urban planning.

\subsection{Application of SuDS}

SuDS capital cost (particularly maintenance cost) is one of the key challenges in their adoption and implementation. In the light of this, it is important to make informed decisions when prioritising SuDS selection at the planning stage.

Fig. 5 illustrates the application of each SuDS type in the set of Pareto optimal solutions. Fig. 5a shows a matrix plot of all optimal solutions and the SuDS applied to each catchment. Fig. 5b, 7c and 7d show the prevalence of each SuDS type against each of the objective functions. The histograms show the proportion of the solution that each SuDS type contributed.

Fig. 5b shows the proportional application of each SuDS type at different total solution cost levels (what percentage each SuDS contributes to solutions at each cost level). For example, RNB make up to $40 \%$ of SuDS applied in the lowest cost solutions. This figure can map SuDS type correlation with capital cost, assisting with SuDS prioritisation when there are budget constraints. One of the key lessons from the optimisation results was the prevalence of RNB in all Pareto-front solutions, mainly due to the dominance of residential areas in the study area and the lower cost of RNB. This can be seen in Fig. 5a, Fig. 5b where RNB is the primary SuDS implementation regardless of cost, with a small variation from $£ 6.0 \mathrm{M}$ to $£ 8.0 \mathrm{M}$ and in the $£ 10.0 \mathrm{M}^{+}$ranges where BIR plays a bigger part in the solutions. Drawing on these, the coverage rate and low cost of RNB, along with its source control function, collectively play a role in promoting FRes and WQRes, as demonstrated in Fig. 5c and Fig. 5d.

There appears to be a trade-off between GSW and BIR in Fig. 5b; GSW is a preferred option in cheaper solutions, mainly due to its lower maintenance cost. Similar behaviour can be observed in Fig. 5c, where GSW is not a desirable option if solutions with maximum FRes are preferred. Nevertheless, if WQRes is prioritised, then GSW is a more desirable option, as shown in Fig. 5d. GNR is utilised more at the cost extremes (cheaper and more expensive) whilst PVP appears to be utilised more in the mid-range solutions. It appears that PVP is a suitable option when solutions with high FRes are prioritised while it is difficult to extend this observation to WQRes. Additionally, it is difficult to extract a correlation between GNR with WQRes and FRes as demonstrated in Fig. 5c and Fig. 5d. 

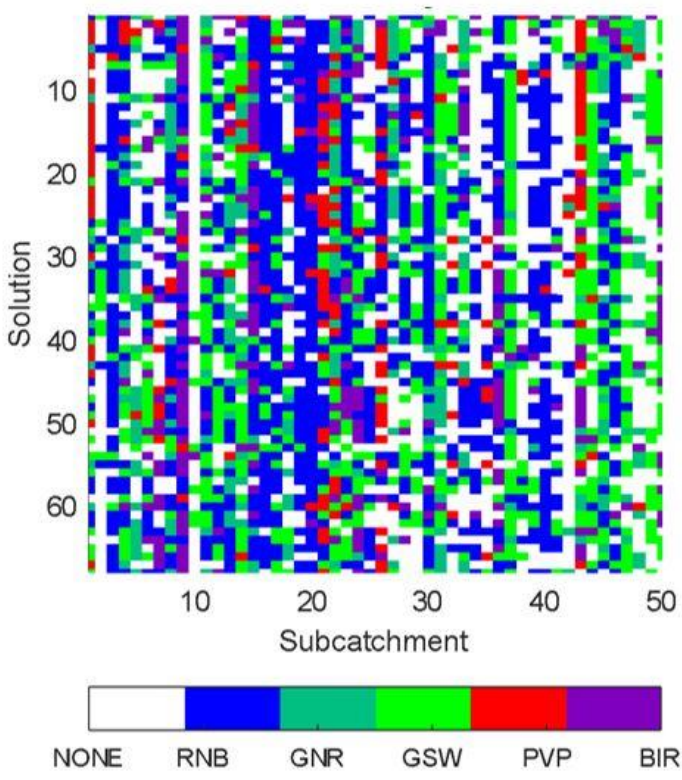

(a)
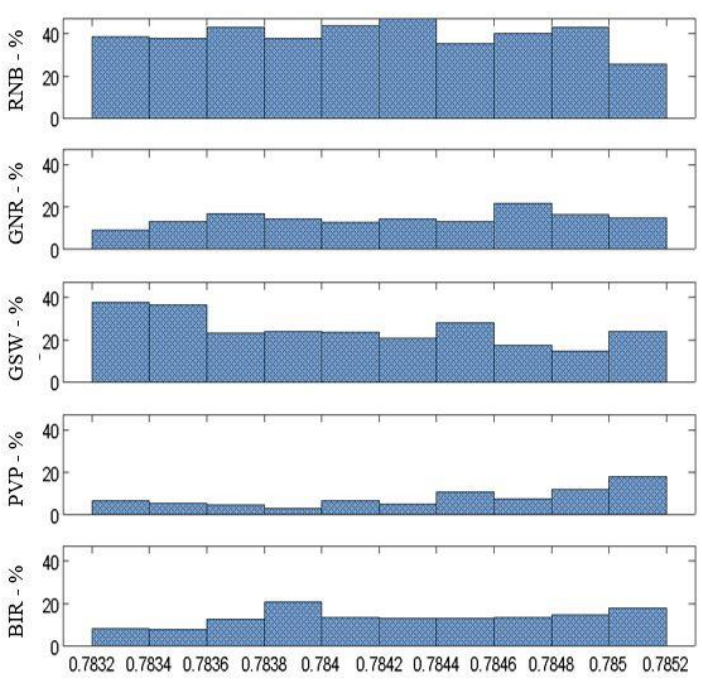

Flood Resilience

(c)
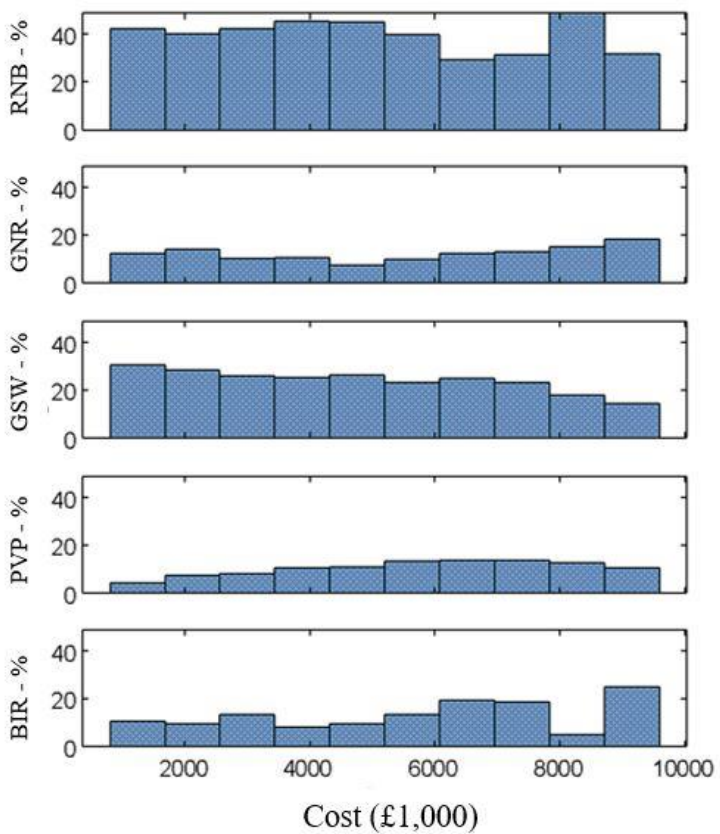

(b)
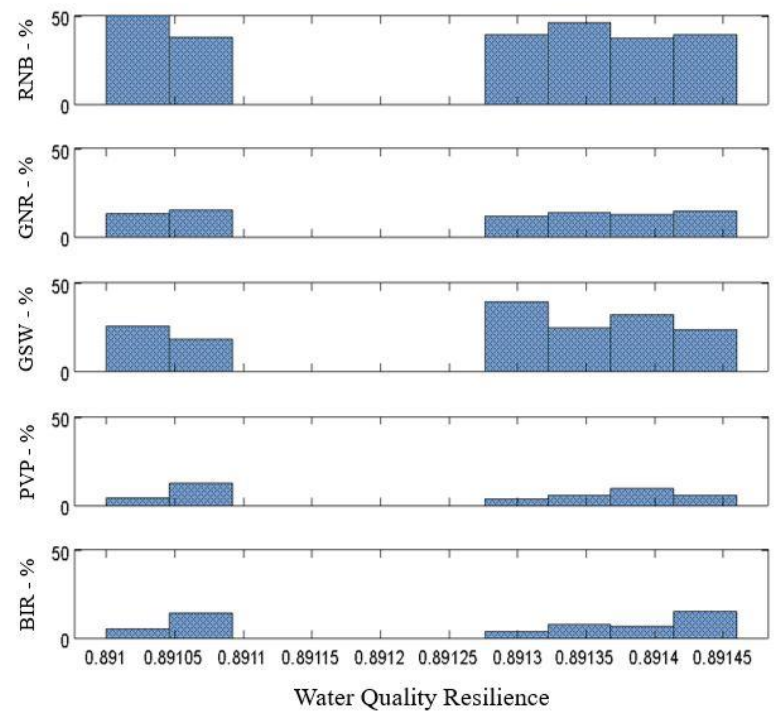

(d)

Fig. 5 - (a) Primary SuDS application by sub-catchment for each solution in the Pareto-Front; (b) Percentage of total application of SuDS for all solutions in the Pareto-Front over Cost;

(c) Percentage of total application of SuDS type for all solutions in the Pareto-Front over FRes; (d) Percentage of total application of SuDS type for all solutions in the Pareto-Front over WQRes

Fig. 6 maps the 'most dominant' SuDS type in each sub-catchment for two selected Pareto-front solutions from Fig. 4. This figure helps to highlight the areas where the same primary SuDS are present in both solutions and helps decision-makers to understand the best dominant option in each sub-catchment as their main likely choice. 
Fig. 6a demonstrates a low cost - high FRes solution with an average WQRes and relatively low iQoL index result. It is evident in Figure 6a that RNB is a preferred option to maintain a high FRes in most of the sub-catchments (particularly the upstream ones) when the cost needs to be kept low. This also highlights the importance of low cost source control SuDS options, such as RNB, in improving FRes in a steep catchment like the study area. However, from a day-to-day quality of life perspective, this solution may not be a priority option due to RNBs' minimal positive impact on quality of life (the smallest of the SUDS types assessed in Table 2). In contrast, Fig. 6b exhibits a high cost - high WQRes - higher iQoL solution. It can be observed that there is a shift towards PVP and BIR for promotion of WQRes in the catchment that increases the cost.

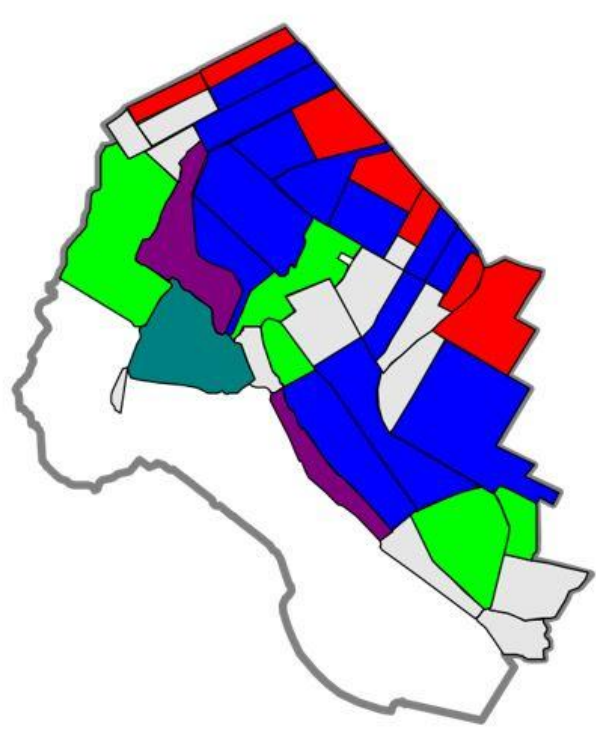

(a)
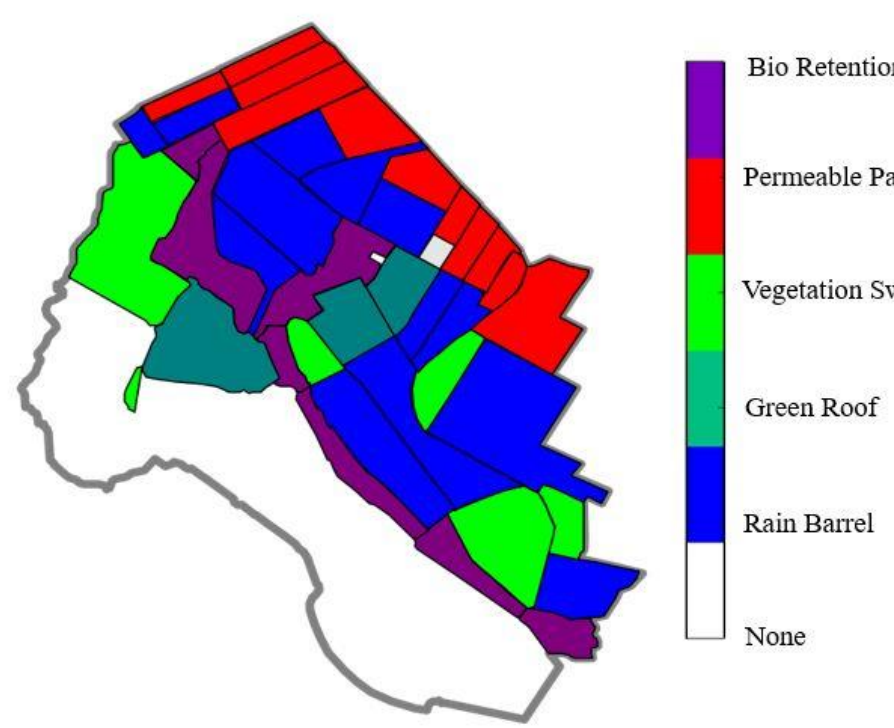

(b)

Fig. 6 - The dominated SuDS implementation in each sub-catchment for (a) a low cost - high FRes solution; (b) a high cost - high WQRes solution

\section{Conclusions}

Promotion of urban resilience is a multi-disciplinary and multi-objective problem and there is no onesize-fit-all solution. Instead we must accept that there is a trade-off between solutions when decisionmaking. In this study, urban flooding (FRes) and water quality resilience (WQRes) were investigated when considering different SuDS types. A resilience-driven multi-objective model was developed to find the trade-off between different solutions, incorporating cost. An improved Quality of Life (iQoL) index was then used to analyse identified solutions for their day-to-day social impacts. Therefore, we argue, the scope of this study as well as the outcomes could be extrapolated to those areas. This study is also representative of many other areas with similar limited drainage systems, where not even conventional drainage systems are well structured. There is the opportunity to adopt sustainable options in both existing and new drainage systems.

In general, the study showed a trade-off between cost and resilience values. However, we did not observe a correlation between flooding and water quality as expected. Instead, water quality resilience introduced stepped results, showing significant improvements in water quality could be achieved by marginally reducing the cost and/or flooding resilience.

Interestingly, the most resilient (i.e. higher flooding and/or water quality resilience values) are expensive but this does not guarantee greater improvements in the quality of life index. Therefore, investing more does not necessarily guarantee the choice of SuDS types that maximise attention to amenity and 
biodiversity. This emphasizes the significant role of quality of life as an assessment criterion, in policy making and decision processes regarding the implementation of SuDS. In addition to the trade-off of resilience and cost, the introduction of the improved quality of life index in the decision process shows the importance of effective spatial distribution of SuDS across the catchment and the effective combination of them, emphasising the need for a strategic approach to SuDS implementation where possible.

Multi-objective optimisation approaches give flexibility for decision makers. For example, bioretention tanks (BIR) and permeable pavements (PVP) play effective roles in improving water quality resilience but this comes with considerable cost increases. So, where the cheapest SuDS options are preferable, a reduction in bio-retention tanks and permeable pavements coverage might be considered. In general, any increase to the coverage of specific SuDS improves water quality resilience and increases costs but the highest improved quality of life index values are seen when SuDS types with higher quality of life weight are selected. Consequently, both cost and improved quality of life index are significantly impacted by the type and spatial distribution of SuDS options implemented. Hence, identifying the appropriate location of the right SuDS options is as critical as identifying the number of units required. This emphasizes the effectiveness of the source control SuDS options for promotion of the water quality and flood resilience, particularly in steep catchments like the case study used.

\section{Limitations}

This project has been a feasibility study which satisfactorily developed a novel resilience-driven multi-objective optimisation model. The model was tested in a real-life case study leading to satisfactory results showing the potential of this model for future research in promotion of urban resilience using SuDS and with conflicting objectives. Nevertheless, the case study used was an ungauged catchment and significantly lacked gauges and monitoring data to fully calibrate the model. Additionally, there are a few studies on SuDS construction and their costs in Brazil, but the methods utilized are not standardized and the data used are outdated. The team has made significant effort to collect as many real data as possible to develop the case study model.

\section{Acknowledgments}

This research project has been funded and supported by Research England through the Quality Related - Global Challenges Research Funding at Anglia Ruskin University (Code: RE522). The team sincerely appreciates the project advisors, Andrew Leadbetter from Peterborough City Council in the UK, Dr Marta Lamparelli from São Paulo State's Environment Agency (CETESB), Pedro Caballero from São Carlos Civil Defence office, Prof Renata Bovo Peres from Federal University of São Carlos, Prof Renato Luiz Sobral Anelli from University of São Paulo for their continuous and in-kind support throughout the project. DGF Cunha thanks CNPq (Conselho Nacional de Desenvolvimento Científico e Tecnológico) for the research productivity grant (Process Number 300899/2016-5).

\section{References}

100ResilientCities, 2016. RioResilient-Resilience Strategy of the city of Rio de Janiero. Rockefeller Foundation. https://drive.google.com/file/d/0Bw6co0uZu4wldGhKWlp6eUhzdEE/view (accessed 28 March 2020).

Aguilar-Barajas, I., Sisto, N., Ramirez, A., and Magaña-Rueda, V., 2019. Building urban resilience and knowledge co-production in the face of weather hazards: flash floods in the Monterrey Metropolitan Area (Mexico). Environmental Science and Policy, 99, 37-47. https://doi.org/10.1016/j.envsci.2019.05.021.

Astaraie-Imani, M., Kapelan, Z., and Butler, D., 2012. Improving the performance of an integrated urban wastewater system under future climate change and urbanisation scenarios. Water and Climate Change, 4(3), 232-243. https://doi.org/10.2166/wcc.2013.078. 
Bevacqua, E., Maraun, D., Vousdoukas, M., Voukouvalas, E., Vrac, M., Mentaschi, L., and Widmann, M., 2019. Higher probability of compound flooding from precipitation and storm surge in Europe under anthropogenic climate change. Science Advances, 5(9), eaaw5531. https://doi.org/10.1126/sciadv.aaw5531.

Beyer, H., and Schwefel, H. P., 2002. Evolution Strategies: A Comprehensive Introduction. Journal of Natural Computing, 1(1), 3-52. https://doi.org/10.1023/A:1015059928466.

Capps, K., Bentsen, C., and Ramírez, A., 2016. Poverty, urbanization, and environmental degradation: urban streams in the developing world. Freshwater Science, 35(1). https://doi.org/10.1086/684945.

Casal-Campos, A., Sadr, S., Fu, G., and Butler, D., 2018. Reliable, Resilient and Sustainable Urban Drainage Systems: An Analysis of Robustness under Deep Uncertainty. Environmental Science and Technology, 52, 9008-9021. https://doi.org/10.1021/acs.est.8b01193.

Chelleri, L., Waters, J., Olazabal, M., and Minucci, G., 2015. Resilience trade-offs: addressing multiple scales and temporal aspects of urban resilience. Environment and Urbanization, 27(1), 181-198. https://doi.org/10.1177/0956247814550780.

CIRIA, 2007. The SUDS Manual (CIRIA C697). London: CIRIA.

CIRIA, 2015. RP 993: Demonstrating the Multiple, Benefits of Suds - A Business Case. Ciria, London, UK. http://www.susdrain.org/resources/best.html (accessed 27 March 2020).

CONAMA, 2005. Resolução conama no. 357. conselho nacional do meio ambiente-conama. http://pnqa.ana.gov.br/Publicacao/RESOLUCAO_CONAMA_n_357.pdf (accessed 27 March 2020).

de Abreu, R., Tett, S., Schurer, A., and Rochar, H., 2019. Attribution of Detected Temperature Trends in Southeast Brazil. Geophysical Research Letters, 46(14), 8407-8414. https://doi.org/10.1029/2019g1083003.

Desouza, K. C., and Flanery, T. H., 2013. Designing, planning, and managing resilient cities: A conceptual framework. Cities, 35, 89-99. https://doi.org/10.1016/j.cities.2013.06.003.

Dhar, T., and Khirfan, L., 2017. A multi-scale and multi-dimensional framework for enhancing the resilience of urban form to climate change. Urban Climate, 19, 72-91. http://dx.doi.org/10.1016/j.uclim.2016.12.004.

Fava, M. C., Abe, N., Restrepo-Estrada, C., Kimura, B. Y., and Mendiondo, E. M., 2018. Flood modelling using synthesised citizen science urban streamflow observations. Journal of Flood Risk Management, 12(S2), e12498. https://doi.org/10.1111/jfr3.12498.

Fletcher, T., Shuster, W., Hunt, W., Ashley, R., Butler, D., Arthur, S., Trowsdale, S., Barraud, S., Semadeni-Davies, A., Bertrand-Krajewski, J.L., Mikkelsen, P.S., Rivard, G., Uhl, M., Dagenais, D., and Viklander, M., 2015. SUDS, LID, BMPs, WSUD and more - The evolution and application of terminology surrounding urban drainage. Urban Water Journal, 12, 525-542. https://doi.org/10.1080/1573062X.2014.916314.

Frantzeskaki, N., 2019. Seven lessons for planning nature-based solutions in cities. Environmental Science and Policy, 93, 101-111. https://doi.org/10.1016/j.envsci.2018.12.033. 
Fu, G., Butler, D., and Khu, S. T., 2008. Multiple objective optimal control of integrated urban wastewater systems. Environmental Modelling and Software, 23(2), 225-234. https://doi.org/10.1016/j.envsoft.2007.06.003.

Grimm, N., Stanley, H., Faeth, N., Golubiewski, C. R., Jianguo, W., and Xuemei, B., 2008. Global Change and the Ecology of Cities. Science, 319. https://doi.org/10.1126/science.1150195.

Hallegatte, S., and Rozenberg, J., 2017. Climate change through a poverty lens. Nature Climate Change, 7, 250-256. https://doi.org/10.1038/nclimate3253.

Huff, F. A., 1967. Time distribution of rainfall in heavy storms. Water Resources Research, 3(4), 10071019. https://doi.org/10.1029/WR003i004p01007.

IBGE, 2015. IBGE. https://cidades.ibge.gov.br/ (accessed 22 June 2020).

IPCC, C. o., 2014. Climate Change 2014: Impacts, Adaptation, and Vulnerability. Part A: Global and Sectoral Aspects. Cambridge and New York: Cambridge University.

Jabareen, J., 2013. Planning the resilient city: Concepts and strategies for coping with climate change and environmental risk. Cities, 31, 220-229. https://doi.org/10.1016/j.cities.2012.05.004.

Jia, H., Yao, H., Tang, Y., Yu, S., Zhen, J., and Lu, Y., 2013. Development of a multi-criteria index ranking system for urban runoff best management practices (BMPs) selection. Environmental Monitoring and Assessment, 185(9), 7915-7933. https://doi.org/10.1007/s10661-013-3144-0.

Jongman, B., 2018. Effective adaptation to rising flood risk. Nature Communications, 9, e1986. https://doi.org/10.1038/s41467-018-04396-1.

Keating, K., Keeble, H., Pettit, A., and Stark, D., 2015. Delivering benefits through evidence - Cost estimation for SuDS - Summary of evidence - Report - SC080039/R9. Environment Agency. http://www.gov.uk/government/publications (accessed 27 March 2020).

Koning, K., Filatova, T., Need, A., and Bin, O., 2019. Avoiding or mitigating flooding: Bottom-up drivers of urban resilience to climate change in the USA. Global Environmental Change, e101981. https://doi.org/10.1016/j.gloenvcha.2019.101981.

Lamond, J., Rose, C., and Booth, C., 2015. Evidence for improved urban flood resilience by sustainable drainage retrofit. Proceedings of the Institution of Civil Engineers - Urban Design and Planning, 168(2), 101-111. http://dx.doi.org/10.1680/udap.13.00022.

Leichenko, R., 2011. Climate change and urban resilience. Current Opinion in Environmental Sustainability, 3(3), 164-168. https://doi.org/10.1016/j.cosust.2010.12.014.

Lim, H., and Lu, X., 2016. Sustainable urban stormwater management in the tropics: An evaluation of Singapore's ABC Waters Program. Hydrology, 538, 842-862. https://doi.org/10.1016/j.jhydrol.2016.04.063.

Mendelsohn, R., Emanuel, K., Chonabayashi, S., and Bakkensen, L., 2012. The impact of climate change on global tropical cyclone damage. Nature Climate Change, 2, 205-209. https://doi.org/10.1038/NCLIMATE1357.

Mendes, R., Andrade, M., C.A., G., Prieto, C., Ávila, F., and Camarinha, P., 2018. Stability Analysis on Urban Slopes: Case Study of an Anthropogenic-Induced Landslide in São José dos Campos. 
Geotechnical and Geological Engineering, 36, 599-610. https://doi.org/a0.1007/s10706-017-0303$\underline{\mathrm{z}}$.

Mugume, S., and Butler, D., 2016. Evaluation of functional resilience in urban drainage and flood management systems using a global analysis approach. Urban Water Journal, 14(7), 727-736. https://doi.org/10.1080/1573062X.2016.1253754.

Municipality of São Paulo, 2012. Secretaria Municipal de Desenvolvimento Urbano. Manual de drenagem e manejo de águas pluviais: gerenciamento do sistema de drenagem urbana. São Paulo: SMDU, 2012.

https://www.prefeitura.sp.gov.br/cidade/secretarias/upload/desenvolvimento urbano/arquivos/ma nual-drenagem_v1.pdf. (accessed 22 June 2020).

Pelling, M., 2003. The Vulnerability of Cities: Natural Disasters and Social Resilience. Abingdon: Earthscan.

PMSC, P. M., 2016. Plano Diretor do Município de São Carlos. Lei no 18.053, de 19 de dezembro de 2016 [Master Plan of the Municipality of Sao Carlos. Law 18.053 of December 19, 2016]. Municipality of Sao Carlos. https://leismunicipais.com.br/plano-diretor-sao-carlos-sp (accessed 27 March 2020).

Pons, N., Pejon, O., and Zuquette, L., 2007. Use of geoprocessing in the study of land degradation in urban environments: the case of the city of São Carlos, state of São Paulo, Brazil. Environmental Geology, 53(4), 727-739. https://doi.org/10.1007/s00254-007-0685-y.

Qin, H., Li, Z., and Fu, G., 2013. The effects of low impact development on urban flooding under different rainfall characteristics. Journal of Environmental Management, 129, 577-585. https://doi.org/10.1016/j.jenvman.2013.08.026.

Sánchez-Rodríguez, R., 2009. Leaning to adapt to climate change in urban areas. A Review of recent contributions. Current Opinion in Environmental Sustainability, 1(2), 201-206. https://doi.org/10.1016/j.cosust.2009.10.005.

Sisto, N., Ramírez, A., Aguilar Barajas, I., and Magaña Rueda, V., 2016. Climate threats, water supply vulnerability and the risk of a water crisis in the Monterrey Metropolitan Area (Northeastern Mexico). Physics and Chemistry of the Earth, Parts A/B/C 91, 2-9. https://doi.org/10.1016/j.pce.2015.08.015.

Stanganini, F., and Augusto de Lollo, A., 2018. O crescimento da área urbana da cidade de São Carlos/SP entre os anos de 2010 e 2015: o avanço da degradação ambiental. Brazilian Journal of Urban Management, 10, 118-128. https://doi.org/10.1590/2175-3369.010.SUPL1.AO14.

Tyler, S., and Moench, M., 2012. A framework for urban climate resilience. Climate and Development, 4(4), 311-326. http://dx.doi.org/10.1080/17565529.2012.745389.

UK Statutory Instruments, 2004. Environmental Assessment of Plans and Programmes Regulations 2004. London: The Stationery Office.

UN-Habitat, 2003. The Challenge of Slums - Global Report on Human Settlements. London: Earthscan Publications. https://www.un.org/ruleoflaw/files/Challenge\%20of\%20Slums.pdf (accessed 27 March 2020).

UN-Habitat, 2010. State of the World's Cities 2010/2011: Bridging the Urban Divide. London: Earthscan. https://unhabitat.org/state-of-the-worlds-cities-20102011-cities-for-all-bridging-the-urban-divide (accessed 27 March 2020). 
UN-Habitat, 2013. State of the World's Cities 2012/2013: Prosperity of Cities. Routledge. https://sustainabledevelopment.un.org/content/documents/745habitat.pdf (accessed 27 March 2020).

UNISDR, 2015. Making Development Sustainable: The Future of Disaster Risk Management. Global Assessment Report on Disaster Risk Reduction. Geneva: United Nations Office for Disaster Risk Reduction. https://www.preventionweb.net/english/hyogo/gar/2015/en/gar-pdf/GAR2015_EN.pdf (accessed 27 March 2020).

Wang, M., Sweetapple, C., Fu, G., Farmani, R., and Butler, D., 2017. A framework to support decision making in the selection of sustainable drainage system design alternatives. Journal of Environmental Management, 201, 145-152. http://dx.doi.org/10.1016/j.jenvman.2017.06.034.

Woods Ballard, B., Wilson, Udale-Clarke, H., Illman, S., Scott, T., Ashley, R., and Kellagher, R., 2015. The SuDS Manual. London: CIRIA C753.

Zhang, Y., Gao, X., Smith, K., Inial, G., Liu, S., Conil, L., and Pan, B., 2019. Integrating water quality and operation into prediction of water production in drinking water treatment plants by genetic algorithm enhanced artificial neural network. Water Research, 164, e114888. https://doi.org/10.1016/j.watres.2019.114888. 